Peshawar Journal of Psychology and Behavioral Sciences, 2016, Vol. 2, No. 1, 31-46

\title{
Depressive Symptoms Among Asthmatic and Non-Asthmatic Patients Attending Khyber Teaching Hospital (KTH), Peshawar
}

\author{
Fatima Zulfiqar ${ }^{1}$ \\ Lady Reading Hospital, Peshawar \\ Syed Sameer Asghar ${ }^{2}$ \\ Layton Rahmatulla Benevolent Trust
}

\begin{abstract}
The purpose of the present research was to investigate the difference between the depressive symptoms among asthmatic and non-asthmatics. The total sample consisted of sixty $(\mathrm{n}=60)$ participants that included thirty $(\mathrm{n}=30)$ asthmatics and thirty $(n=30)$ non-asthmatics both males and females. Convenient sampling technique was used in sample selection. The Beck Depression scale was used. Data was collected from the asthmatic patients in the Khyber Teaching Hospital. It was hypothesized that asthmatics will have more depressive symptoms than the non-asthmatics. The results supported the hypothesis $(\mathrm{p}<0.01)$. The female asthmatics scored slightly higher on scale of depression than male asthmatics.
\end{abstract}

Keywords. Depression, asthmatics, non-asthmatics, females and males

Asthma is a chronic respiratory general medical illness or disease that may affect all age groups. Inheritance and environment both play significant role is causing asthma environmental factors include, inhaling dust and other toxins, nature of occupation, and persistent exposure to stressors (WHO, 2010). Asthma is described as episodic, reversible bronchospasm developing from exaggerated Bronchoconstrictor response to number of stimuli. The cause of bronchial hyperactivity is not completely known, but it is generally believed that the cause of asthma is persistent bronchial inflammation.

${ }^{1}$ Coordinator, Preventive Cardiology, Lady Reading Hospital, Peshawar

${ }^{2}$ Resident Medical Officer, Layton Rahmatulla Benevolent Trust, Akora Khattak 
Clinically, asthma is manifested by episode dysponea (Difficulty in breathing), cough and wheezing (a soft whistling sound during expiration).

It is classified into following categories.

\section{Extrinsic asthma}

Extrinsic asthma is caused by allergens. Therefore, it is also called as allergic asthma. It is started by a hypersensitive reaction produced by contact to an extrinsic antigen.

\section{Intrinsic asthma}

The causal agent of intrinsic asthma is not known that is why it is very difficult in terms of treatment. Wide range of stimuli that may have little or no effect in normal subject can cause bronchospasm.

Asthma is one of the most widespread chronic respiratory diseases. About 100-150 million people suffer from asthma worldwide. According to the calculations of World Health Organization the cost of caring for asthma exceed that of tuberculosis and AIDS/HIV combined. These figures highlight the extent of the load associated with this disease and its effects on person's emotions and quality of life. The high load of asthma seems to be associated to poor asthma control, that appears to be significantly associated with recurrent asthmatic symptoms (wheezing, dyspnea, night-time waking), bronchodilator use, functional impairment (noticeable decline in participation in social and physical activities, absenteeism) and poorer pulmonary functioning. World Health Organization: Bronchial asthma, 2000; CDC, National Center for Health Statistics, 2000-2001).

Several emotional and psychosocial elements have been found to be associated with uncontrolled asthma and it's impact on the quality of life such as depression, anxiety, and inappropriate coping strategies. However, some of the studies have assessed the effect of chronic psychopathology, i.e., psychological disorders on levels of asthma control and quality of life. Rates of certain psychological disorders (e. g., anxiety disorders such as panic attacks and major depressive disorder) have been reported to be relatively double among asthmatics as 
compared to the general population. It is imperative to do in depth investigations for assessing the effects of psychiatric disorders on levels of asthma, its control and associated outcomes.

Depressive illness is a mood disorder characterized by core symptoms of low mood, loss of interest, reduced energy level, impairment in social, occupational and interpersonal functions. It may be mild, moderate or severe with or without psychotic features. Many patients of asthmatic diseases report to have comorbid depressive illness of variable levels of severity due to the emotional and psychological pressures associated with the disease. As a result of very little research in this area currently there is a lack of data on the exact statistics of prevalence of depression among asthmatics.

The severity of psychological disorders is apparently associated with the intensity of poor controlled asthma, impaired routine functioning, quality of life and poor compliance to treatment schedules. Nevertheless, the psychological and physical functions underlying psychological disorders in asthma are not completely known. The extent of psychological elements such as cognitive and behavioral correlates of personality traits describes the manifestation of psychiatric disorders among patients with asthma.

Neuroticism is a basic personality trait characterized as a predisposition to experience distressing and negative emotions, and is evidently linked to mental health psychological disorders including ability to cope with stress, anxiety and depression, as well as poorly controlled asthma.

Perceived stress in relation to life events is a cognitive correlate of neuroticism that is produced by one's own conditioning, values and belief. According to research reports, stress has negative influence on the onset, hospitalization, severity, and prolonged medication use, and prognosis of asthma. The manifestation of perceived stress and neuroticism might consequently explain an increase in psychological comorbidities among asthma patients. Similarly, studies proposed perceived stress and neuroticism also contribute to obesity or higher body mass index (BMI) and perceived health problems. Relapse of asthma is reportedly found to be associated with physical factors, which further cause serious anxiety symptoms in patients suffering from asthma. 
Major depressive disorder is diagnosed when patient report two weeks or more with symptoms of depression i.e. at least one or more major depressive episodes or less interest accompanied by at least four addition symptoms of depression (DSM IV).

Depression the most frequent and widely diagnosed mental disorder, effecting both women $(21.3 \%)$ and men $(12.7 \%)$ and for people living with diseases that can decrease their quality of life such as asthma (Barnes PJ, Jonsson B, Klim JB, 1996; Hoskins G, McCowan C, Neville RG, Thomas GE, Smith B,Silverman R, 2000; Miles JF, Garden GM, Turncliffe WS, Clayton RM, Ayres JG, 1997). Poorly managed asthma can sometimes prevent the patients from carrying out their routine tasks and doing all those tasks they want to accomplish physically, that leads the patients to frustration and isolation (Cluley S, Cochrane GM, 2001; Goldney RD, Ruffin R, Fisher LJ, Wilson DH. Asthma, 2003; Janson C, Bjornsson E, Hetta J, Boman G, 1994; Van der Schoot TA, Kaptein AA, 1990). Major depressive disorder has the tendency to be transmitted through heredity or learning and is about 1.5-3 times more prevalent among first degree biological relative of persons with this disorder than among the general people (Nejteck VA, Brown ES, Khan DA, Moore JJ, Van Wagner J, 2001; Perna G, Bertani A, Politi E, Colombo G, Bellodi L, 1997; Nacimento I, Nardi AE, Valenca AM, et al, 2002; Goodwin RD, Olfson M, Shea S, et al, 2003; Goodwin RD, Jacobi F, Thefeld W, 2003; [15] Bateman ED, Boushey HA, Bousquet J, et al, 2004).

Chaney, Mullins, Uretsky, Pace, Werden, Hartman (1999) investigated the impacts of experimentally produced learned helplessness in young adults and older adolescents. The results revealed that age-old asthma patients might be highly prone to learned helplessness and depression, particularly decreased problem solving skills, in response to environmental no contingency. The sample of the study comprised of thirty-nine participants with the age range of 18-24 years and with histories of long-standing asthma and an age-matched healthy cohort received either contingent or no contingent feedback on an experimental task. Participants were pre and post test tested through depression scale they were also investigated through measures of mood, expectancy, and attributions related to experimental task performance. Robert D Goldney, (2003) assessed the association between asthma and depression and quality of life through face-to-face omnibus survey method. The prevalence of asthma was $9.9 \%$ and it was found to be highly associated 
with depression particularly among those who experienced dysponea, sleep disturbance due to asthma and symptoms of asthma at morning. The same group showed decline in the quality of life that means impaired in quality of life due to asthma.

Tanya A Zielinski, Sherwood Brown, Vicki A. Nejtek, David A. Kha Jacob J. Moore, and A. John Rush (2000) used English language databases to find articles on association between asthma and depression, the search terms included depression, asthma, mood and dysthymia. Their literature review suggests depressive symptoms are more prevalent among asthmatic than any other medical condition and general population. Depression is highly associated with asthma morbidity and mortality.

Eric. L Hurwitz (2003) investigated the association between personal and work related stressors with depression and perceived stress, and ascertained if these correlations are changed by physical inactivity and asthma. Data from 2,902 respondents of the 1998-1999 California Work and Health Survey (CWHS) were used. The CWHS included items on asthma history, exercise, personal stressors, decision latitude on the job, psychological and physical job demands and perceived stress and depression as well as performance at workplace such as decision making was observed to be impaired due to asthma.

A study conducted by Kevin A. Hommel et al (2003) shown the differential contribution of uncertainty associated with illness associated with depression and anxiety among older adolescents with childhood history of asthma. Total number of fifty-six participants participated in the study. Results revealed that illness uncertainty was found to be significantly associated with anxiety after controlling for the effects of depressive symptoms, disease parameters and demographics; illness uncertainty was not found to be significantly associated with depression.

Galil, Nora (2000) examined the possible contribution of genetic vulnerability, immunological compromise, allergic sensitivity, and psychological stressors all are contributory factors of asthma and its onset and severity. Increase in depression decrease the level of compliance for controlling asthma that further worsen the prognosis, which ultimately becomes problematic for caring for the asthmatic child. The severity of the asthma and depression may be prevented or controlled through the early interventions for addressing the comorbid 
depressive disorders. More importantly the finding of the present study suggests that treatment of depression reduces the mortality rate among patients with severe asthma.

Recent research found that children with asthma are equally prone to risks associated with psychological problems such as anxiety, depression, and problems in their daily routine and social activities involving relations with peer. Similar study was conducted with urban children intended to investigate the association between asthma, depression and anxiety and number of aspects of social activities in urban children. Findings revealed impairment in social activities among children with asthma form urban environment as compared to children without asthma. It was also suggested that impairment in social activities further leads to both anxiety and depression among children with asthma as compared to non-asthmatic children. Specifically, children who showed higher level of anxiety and depression were more likely to have more impairment in interpersonal relationships.

Psychological problems are complex in nature for identifying the exact cause of the problem. It is difficult to actually connect asthma with psychological disorders, similarly it is difficult to unfold what is actually causing the psychological symptoms.

The purpose of study is to find out association between the asthma and depression. The study was further intended to investigate the role of gender in depression among asthmatics and non asthmatic group.

\section{Objectives}

1. To investigate depression among asthmatic and non-asthmatic patients.

2. To find out the differences and level of depression among male and female Asthmatic and non-asthmatic Patients.

\section{Hypotheses}

1. Diagnosed asthmatic patients are more prone to develop depression as compared to diagnosed non-asthmatic persons. 
2. Diagnosed female asthmatic patients are more prone to develop depression, than the diagnosed male asthmatic patients.

\section{Method}

\section{Sample}

The sample consisted of sixty $(\mathrm{N}=60)$ participants, that included thirty $(n=30)$ asthma patients and thirty $(n=30)$ normal non asthmatics. In experimental group 30 asthmatic participants were selected from Khyber Teaching Hospital Peshawar. Participants with asthma for the study were recruited from Out Patient Department (OPD) of Khyber Teaching Hospital, Peshawar. All asthmatic patients with other medical condition were excluded from the sample. Asthmatics patients selected consisted of those already diagnosed six moths or earlier with asthma by a Physician and have been persistently under treatment for the last six months or more for asthma. Participants with other medical or psychiatric disorders were excluded from the study.

In control group 30 participants were selected. Who were further divided into 15 females and 15 males. Those participants were randomly selected from Peshawar University.

\section{Instruments}

Beck Depression Scale is a worldwide-accepted highly reliable and valid scale for measuring depressive symptoms. This scale is not designed to make diagnosis but to investigate the symptoms of depression in a person.

\section{Procedure}

This research was conducted on thirty $(n=30)$ diagnosed asthmatic and thirty $(n=30)$ non-asthmatic persons. The educated participants were given questionnaires to be filled whereas illiterate participants were interviewed. The following instructions were given to the participants. 
"I am going to give you a questionnaire to you. This questionnaire is about your moods. Your task is to answer the questions written in the questionnaire. This questionnaire has no right and no wrong. So give answer honestly, you opinion matters. "

However they were debriefed while giving them questionnaire the asthmatic patients were selected from the OPD of the Khyber Teaching Hospital of Peshawar. Patients belong to different surrounding area of Peshawar. The non-asthmatic 30 person were randomly selected from Peshawar. They were given the same instruction as described above and also debriefed afterwards.

After the completion of questionnaire all the participants were thanked for their valuable time and sharing their personal information.

After collecting the data to analyze SPSS program was used for analysis. Applied t-test on asthmatic and non-asthmatic groups, on males, females of asthmatic group, on male of asthmatic and non-asthmatic group and on females of asthmatic and non-asthmatic groups, we conducted a differential research because to induce depression experimentally is unethical.

\section{Results}

Table 1

Difference Between Asthmatic and Non-Asthmatics on Depression $(\mathrm{N}=60)$

\begin{tabular}{llllllllll}
\hline $\begin{array}{l}\text { Asthmatic } \\
(\mathrm{n}=30)\end{array}$ & \multicolumn{2}{l}{$\begin{array}{l}\text { Normal } \\
(\mathrm{n}=30)\end{array}$} & & & & & & & \\
\hline $\mathrm{M}$ & $\mathrm{SD}$ & $\mathrm{M}$ & $\mathrm{SD}$ & $\mathrm{t}(58)$ & $\mathrm{P}$ & \multicolumn{2}{c}{$\mathrm{CI} 95 \%$} & & \begin{tabular}{c} 
Cohen's \\
\cline { 7 - 8 }
\end{tabular} \\
23.80 & 7.98 & 12.87 & 8.31 & 5.19 & .001 & 6.72 & 15.14 & 1.34 \\
\hline
\end{tabular}

Table 1 shows the difference between asthma patients and nonasthmatics on depression scale. The asthma patients $(\mathrm{M}=23.80$, $\mathrm{SD}=7.98)$ scored higher than non asthmatics $(\mathrm{M}=12.87, \mathrm{SD}=8.31), \mathrm{t}(58)$ 
$=5.19$ with mean difference $10.93, \mathrm{p}<.001, \mathrm{~d}=1.3$, the effect size is higher than the Cohen's (1988) convention for largest effect size .80 .

Table 2

Gender Difference Between Asthmatics on Depression (N=30)

\begin{tabular}{|c|c|c|c|c|c|c|c|c|}
\hline $\begin{array}{l}\text { Male } \\
(\mathrm{n}=14)\end{array}$ & & $\begin{array}{l}\text { Female } \\
(n=16)\end{array}$ & & & & & & \\
\hline \multirow{2}{*}{ M } & \multirow{2}{*}{ SD } & \multirow{2}{*}{$\mathrm{M}$} & \multirow{2}{*}{ SD } & \multirow{2}{*}{$\mathrm{t}(28)$} & \multirow{2}{*}{$\mathrm{P}$} & CI 95 & & \multirow{2}{*}{$\begin{array}{c}\text { Cohen's } \\
\text { d }\end{array}$} \\
\hline & & & & & & LL & UL & \\
\hline 25.31 & 6.91 & 22.07 & 9.00 & 1.11 & .27 & -2.72 & 9.20 & .40 \\
\hline
\end{tabular}

Table 2 shows the gender difference between the scores of male and female asthma patients on depression scale. The male participants suffering from asthma $(\mathrm{M}=25.31, \mathrm{SD}=6.91)$ scored slightly higher than females asthmatics $(\mathrm{M}=22.07, \mathrm{SD}=9.00), \mathrm{t}(28)=1.11$ with mean difference $3.24, \mathrm{p}>.05, \mathrm{~d}=0.40$, shows small effect size suggested by Cohen's (1988) convention for levels of effect size.

Table 3

Gender Difference Between Non-Asthmatics on Depression $(\mathrm{N}=30)$

\begin{tabular}{|c|c|c|c|c|c|c|c|c|}
\hline $\begin{array}{l}\text { Male } \\
(n=11)\end{array}$ & & $\begin{array}{l}\text { Female } \\
(n=19)\end{array}$ & & & & & & \\
\hline \multirow{2}{*}{ M } & \multirow{2}{*}{$\mathrm{SD}$} & \multirow{2}{*}{ M } & \multirow{2}{*}{ SD } & \multirow{2}{*}{$t(28)$} & \multirow{2}{*}{$\mathrm{P}$} & \multicolumn{2}{|c|}{ CI 95\% } & \multirow{2}{*}{$\begin{array}{l}\text { Cohen's } \\
\text { D }\end{array}$} \\
\hline & & & & & & LL & $\mathrm{UL}$ & \\
\hline 12.64 & 8.26 & 12.87 & 8.31 & -.11 & .91 & -6.93 & 6.20 & 0.02 \\
\hline
\end{tabular}

Table 3 shows the difference between the scores of male and female non-asthmatics on depression scale. The male non-asthma persons $(\mathrm{M}=12.64, \mathrm{SD}=8.26)$ scored slightly lower than female nonasthmatics $(\mathrm{M}=12.87, \mathrm{SD}=8.31), \mathrm{t}(28)=-.11$ with mean difference $3.206, p>.05, d=0.02$, a very low effect size less than the lowest value suggested by Cohen's (1988). 
Table 4

Difference Between the Scores of Married and Unmarried Asthmatics on Depression $(\mathrm{N}=30)$

\begin{tabular}{|c|c|c|c|c|c|c|c|c|}
\hline \multicolumn{2}{|c|}{$\begin{array}{l}\text { Married } \\
(\mathrm{n}=15)\end{array}$} & \multicolumn{7}{|c|}{$\begin{array}{l}\text { Unmarried } \\
(\mathrm{n}=15)\end{array}$} \\
\hline \multirow{2}{*}{$\mathrm{M}$} & \multirow{2}{*}{ SD } & \multirow{2}{*}{$\mathrm{M}$} & \multirow{2}{*}{ SD } & \multirow{2}{*}{$\mathrm{t}(28)$} & \multirow{2}{*}{$\mathrm{P}$} & CI 95" & & Cohen's \\
\hline & & & & & & LL & UL & $\mathrm{D}$ \\
\hline 25.93 & 6.39 & 21.67 & 9.02 & 1.49 & .14 & -1.58 & 10.11 & .54 \\
\hline
\end{tabular}

Table 4 shows the difference between the scores of married and unmarried asthmatic patients on depression scale. The married asthma patients $(\mathrm{M}=25.93, \mathrm{SD}=6.39)$ scored slightly higher than the unmarried asthmatics $(\mathrm{M}=21.67, \mathrm{SD}=9.02), \mathrm{t}(28)=1.49$ with mean difference 4.26, $\mathrm{p}>.05, \mathrm{~d}=0.54$, indicates medium effect size according to the Cohen's (1988) convention for levels of effect size.

Table 5

Difference Between the Scores of Married and Unmarried NonAsthmatics on Depression $(\mathrm{N}=30)$

\begin{tabular}{|c|c|c|c|c|c|c|c|c|}
\hline \multicolumn{2}{|c|}{$\begin{array}{l}\text { Married } \\
(\mathrm{n}=08)\end{array}$} & \multicolumn{6}{|c|}{$\begin{array}{l}\text { Unmarried } \\
(\mathrm{n}=22)\end{array}$} & \multirow{3}{*}{$\begin{array}{c}\text { Cohen's } \\
\text { d }\end{array}$} \\
\hline \multirow{2}{*}{$\mathrm{M}$} & \multirow{2}{*}{ SD } & \multirow{2}{*}{$\mathrm{M}$} & \multirow{2}{*}{ SD } & \multirow{2}{*}{$\mathrm{t}(28)$} & \multirow{2}{*}{$\mathrm{P}$} & CI 95 & & \\
\hline & & & & & & $\mathrm{LL}$ & $\mathrm{UL}$ & \\
\hline 15.38 & 9.33 & 11.95 & 7.94 & .99 & .32 & -3.61 & 10.45 & .41 \\
\hline
\end{tabular}

Table 5 shows the difference between the scores of married and unmarried non-asthmatic patients on depression scale. The married nonasthmatic participants $(\mathrm{M}=15.38, \mathrm{SD}=9.33)$ scored higher than unmarried non asthmatics $(\mathrm{M}=11.95, \mathrm{SD}=7.94), \mathrm{t}(28)=.99$ with mean difference $3.42, \mathrm{p}>.05, \mathrm{~d}=0.41$ effect size shows medium level of effect size according to the Cohen's (1988) convention for levels of effect size.

\section{Discussion}


The present research study is the association between the asthma and depression. This study included experimental and control group. Experimental group consisted of member of diagnosed asthmatic patient on which Beck depression scale was administered. The control group consists of the diagnosed non-asthmatic persons on which Beck depression scale was conducted. Both groups included 30 participants each comprising of both males and females. The total sample was consisted of sixty participants $(\mathrm{N}=60)$.

The first hypothesis of the study stated that diagnosed asthmatic patients are prone to develop depression as compared to diagnosed nonasthmatic person. After collecting the results we conducted t-test to determine the difference between asthmatic and non-asthmatic persons. So as shown in the table no 1 there is a significant difference between the asthmatic and non-asthmatic person on Beck depression scale. As it is generally observed that when someone is ill one is feeling helpless and depressed. So asthmatic is a long duration disease, becoming depressive in asthma is something astonishing.

This study was conducted in winter and spring. This is the favorable seasons for asthmatic attacks. In winter patients are allergic from coldness hence patients are more prone to asthmatic attacks. In spring some patients are allergic from pollen grains hence are more prone to asthmatic attacks. The study was conducted in peak season for asthma, as the intention was to have actual picture of the effect of asthma on depression. This could have resulted in high scores of depression. This is a need to study association of asthma with depression keeping in view the seasonal factors.

The second hypothesis states that diagnosed female asthmatic patients are more prone to develop depression than the diagnosed male asthmatic patients. In order to check the significance t-test was conducted on depression scores of males and females of asthmatic group as shown in table 2, 3 the results indicate not significant difference between these two groups it means that both males and females are equally affected by asthma. Although do not affect incr3easing depressive symptoms. Even if the difference exists it is negligible.

Another statistical tests was conducted to analyze the second hypothesis one test conducted on males of asthmatic and non-asthmatic 
groups as shown in table 2. Results indicates that there is no significant difference between these two groups on the variable of depression score so again there is no difference between asthmatic and non-asthmatic regardless of the common gender. The gender of the asthmatic does not affect the onset of depression. Second test was conducted on females of both asthmatic and non-asthmatic groups as shown in table 2, 3. The results of t-test indicated significant difference between these two groups. So when the gender variable was kept constant even then the depression scope of the experimental group and a control group differ significantly.

Table 2 and 3 shows no significant difference between asthmatic and non-asthmatic male and female patients. Table 4 and 5 shows no significant difference between asthmatic and non-asthmatic married and single patients on the variable of depression score. So the findings support the first hypothesis, i.e., asthmatics are more prone depression than those with no medical or psychiatric condition(s). It is concluded from the findings of the present study that there is a significant difference between asthma patients and non-asthmatics on scores of depression, i.e., asthmatics scored significantly higher on depression than non-asthmatics.

\section{Summary}

Asthma is a chronic medical disease that affects airways of a person, which causes symptoms like wheezing (a whistling sound when one breathes), chest tightness, coughing, and trouble breathing, especially in the morning and at night.

Asthma cannot be treated completely, but most asthma patients can control it so that they have infrequent and few symptoms and can live physically active lives.

The purpose of this study was to find out the association of depression in asthmatic and non-asthmatic. The hypotheses, "diagnosed asthmatic patients are prone to develop depression as compare to diagnosed non-asthmatic persons" and "diagnosed female asthmatic patients are more prone to develop depression than the diagnosed male asthmatic patients. 
Keeping this view in mind data was collected from sample of $\mathrm{N}=60$ in which 30 were asthmatic and 30 were non-asthmatic. The asthmatic patients were selected from the different wards of Khyber Teaching Hospital while the non-asthmatics were selected from different areas of Peshawar. These asthmatic and non-asthmatic were further divided in to male and female categories. After collecting the data it was analyzed through SPSS. Result showed that data support the hypotheses. So it was concluded that asthmatic patients are more prone to develop depression as compared to non-asthmatic patients and female asthmatic patients are more prone to develop depression as compare to nonasthmatic.

\section{Conclusion}

The present study finds out positive association between asthma and depression. Two groups asthmatic and non-asthmatic. These two groups were further divided not male and females category. The results revealed that there is significant difference between the two groups asthmatic and non-asthmatic. Whereas

male females differences were significant in the asthmatic and non-asthmatic group. But when find out within asthmatic group it turned out to be not significant. These findings also suggest that medical practitioner may need to focus on the possible impact of negative mood states when assessing levels of asthma control and implementing treatment strategies.

Finally from the significantly high scores obtained by asthmatic on depression scale, it is concluded that asthma may contribute to the development of depression. Depression caused by the asthma is not affected by gender differences. It is recommend that the clinical evaluation of asthmatic patients should importantly include their mental wellbeing. Proper awareness be created among physicians through training to increase their clinical acumen at recognizing comorbid psychiatric disorder and make appropriate decision which may include referral. There is great need for creating awareness at larger scale about the comorbidity 
of depression and asthma, and their associated factors as well as preventions. General practitioners need to be actively involved in creating awareness about psychiatric disorders and medical conditions, their treatments and referrals when needed. It is also suggested that focus on life style modifications are required for better outcome of treatment of asthma and depression, and prevention of such problems. This will undoubtedly improve the management of asthmatics as well as their quality of life.

\section{References}

Barnes PJ, Jonsson B, Klim JB. The costs of asthma. EurRespir J 1996; 9: 636-42.

Berz.j.B., Recent research has shown that kids with asthma may also be at risk for psychological problems such as depression, anxiety, and problems in their social lives including peer interaction. Journal of child and Adolescents psychiatric Nursing.

CDC, National Center for Health Statistics. Asthma prevalence, health care use and mortality, 2000-2001. Available at http://www.cdc.gov/nchs/products/pubs/pubd/hestats/asthma/asth ma.htm.

Chaney,J.: Mulins, L.L: Urestsky, D.L. ;pace, T.M.; Werden, D.;Hartman, v.1. An experimental examination of learned helplessness in older adolescents and young adults with longstandingn asthma J PediairPsychol June 1999 24(3):259-70

Cluley S, Cochrane GM. Psychological disorder is asthma is associated with poor control and poor adherence to inhaled steroids. Respir Med 2001; 95: 37-9.

Goldney RD, Ruffin R, Fisher LJ, Wilson DH. Asthma symptoms associated with depression and lower quality of life: a population survey. Med J Aust 2003; 178: 437-41.

Goldney, R.D Asthma Symptoms associated with depression and lower quality of life. The Mledical Journal of Australia 2003, 10 Feb 2003.

Peshawar Journal of Psychology and Behavioral Sciences, 2016, Vol.2, No. 1, 31-46 
Goodwin RD, Jacobi F, Thefeld W. Mental disorders and asthma in the community. Arch Gen Psychiatry 2003; 60: 1125-30.

Horumel, K.A Hoff, A.: Mullins. L.L,; Anxiety and Depression in Older Adolescents with long-Standing Asthma: the Role of Illness Uncertainty. Chilren Health Care 2003, vol; 32, No. 1, pages 5163.

Hoskins G, McCowan C, Neville RG, Thomas GE, Smith B, Silverman R. Risk factors and costs associated with an asthma attack. Thorax 2000; 55: 19-24.

Hurtwitz, D.C lindings\&om the 1 998- 1999 do Asthma and Physical inactivity influence the Associations of Personal and Job Stressors with perceived stress

Janson C, Bjornsson E, Hetta J, Boman G. Anxiety and depression in relation to respiratory symptoms and asthma. Am J RespirCrit Care Med 1994; 149: 930-4.

Krommy das, G.C; Gourgouliaus, K.I.; Angelopoulous, n.y.; Andreou, P.A; Moyvdas, P.a; left-handedness and Parental Psychopathology in the Course of Bronchial Asthma in Childhood Pediatric , Asthma Allergy, jrnm8uology June 2002, Vol. 15, no, 3: 145-152

Kumar, V; Corton, R.S.; Robbine S.L; (1997) Basic Pathology $\left(6^{\text {th }}\right.$ .cd.).Department of Pathology, university of Texas: w.B. Saunders company

Miles JF, Garden GM, Turncliffe WS, Clayton RM, Ayres JG. Psychological morbidity and coping skills in patients with brittle and non-brittle asthma: A case-control study. ClinExp Allergy 1997; 27: 1151-9.

Nejteck VA, Brown ES, Khan DA, Moore JJ, Van Wagner J, PerantieDC. Prevalence of mood disorders and relationship to asthma severity in patients at an inner-city asthma clinic. Ann Allerg Asthma Immunol 2001; 87: 129-33.

Nkporbu Aborlo Kennedy, Ojule Inumanye Nkechi, Stanley Princewill Chukwuemeka. Prevalence of Depressive Illness Among Patients with Asthmatic Disease Attending the University of Port Harcourt Teaching Hospital (UPTH). American Journal of Psychiatry and Neuroscience. Vol. 4, No. 1, 2016, pp. 13-17. doi: $10.11648 /$ j.ajpn.20160401.13 
Nora,g. Depression and asthma in children Current opinion pediatrics 12(4);331-335, august 2000.

Orgcrta, A. ohio University Study explores link between depression anxiety and asthma in Puerto rican children June 2002.

Tanya A Zielinski, Sherwood Brown, Vicki A. Nejtek, David A. Kha Jacob J. Moore, and A. John Rush (2000). Depression in Asthma: Prevalence and Clinical Implications. Prim Care Companion J Clin Psychiatry. 2000 Oct; 2(5): 153-158

Van der Schoot TA, Kaptein AA. Pulmonary rehabilitation in an asthma clinic. Lung 1990; 168: 495-501.

World Health Organization: Bronchial asthma. http:/www.who.int/mediacentre/factsheets/fs206/en/print.html(re vised January 2000).

Zielniski, T.A.; Brown, E.S, Nejtek, V.A.; Khan D.A; Jacob, 3.; Moore, B.S.\& Rush, J, Depression in Asthma: Prevalence and Clinical implication, Clinical Psychiatry, V.2 (5); Oct 2000, 2 (5): 153-158

Eric. L Hurwitz (2003). Do Asthma and Physical Inactivity Influence the Associations of Personal and Job Stressors with Perceived Stress and Depression? Findings from the 1998-1999 California Work and Health Survey. The official journal of American Epidemiology. Volume 13. No. 5. Pages 358-368 